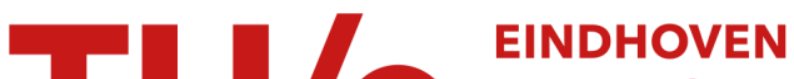 \\ UNIVERSITY OF \\ TECHNOLOGY
}

\section{Hydrogen transport through the $\mathrm{V}-\mathrm{Cr}-\mathrm{Al}$ alloys}

\section{Citation for published version (APA):}

Huang, F., Li, X., Shan, X., Guo, J., Gallucci, F., van Sint Annaland, M., \& Liu, D. (2020). Hydrogen transport through the V-Cr-Al alloys: hydrogen solution, permeation and thermal-stability. Separation and Purification

Technology, 240, [116654]. https://doi.org/10.1016/j.seppur.2020.116654

\section{Document license: \\ TAVERNE}

DOI:

10.1016/j.seppur.2020.116654

Document status and date:

Published: 01/06/2020

\section{Document Version:}

Publisher's PDF, also known as Version of Record (includes final page, issue and volume numbers)

\section{Please check the document version of this publication:}

- A submitted manuscript is the version of the article upon submission and before peer-review. There can be important differences between the submitted version and the official published version of record. People interested in the research are advised to contact the author for the final version of the publication, or visit the $\mathrm{DOI}$ to the publisher's website.

- The final author version and the galley proof are versions of the publication after peer review.

- The final published version features the final layout of the paper including the volume, issue and page numbers.

Link to publication

\section{General rights}

Copyright and moral rights for the publications made accessible in the public portal are retained by the authors and/or other copyright owners and it is a condition of accessing publications that users recognise and abide by the legal requirements associated with these rights.

- Users may download and print one copy of any publication from the public portal for the purpose of private study or research.

- You may not further distribute the material or use it for any profit-making activity or commercial gain

- You may freely distribute the URL identifying the publication in the public portal.

If the publication is distributed under the terms of Article $25 \mathrm{fa}$ of the Dutch Copyright Act, indicated by the "Taverne" license above, please follow below link for the End User Agreement:

www.tue.nl/taverne

Take down policy

If you believe that this document breaches copyright please contact us at:

openaccess@tue.nl

providing details and we will investigate your claim. 


\title{
Hydrogen transport through the V-Cr-Al alloys: Hydrogen solution, permeation and thermal-stability
}

\author{
Feifei Huang ${ }^{\mathrm{a}}$, Xinzhong $\mathrm{Li}^{\mathrm{a}}{ }^{\mathrm{b}, *, 1}$, Xingrun Shan ${ }^{\mathrm{a}}$, Jingjie Guo ${ }^{\mathrm{a}}$, Fausto Gallucci ${ }^{\mathrm{c}}$, \\ Martin van Sint Annaland ${ }^{\mathrm{d}}$, Dongmei Liu ${ }^{\mathrm{e}, *, 1}$ \\ ${ }^{a}$ School of Materials Science and Engineering, Harbin Institute of Technology, Harbin 150001, PR China \\ ${ }^{\mathrm{b}}$ School of Iron and Steel, Soochow University, Suzhou 215000, PR China \\ ${ }^{\mathrm{c}}$ Inorganic Membranes and Membrane Reactors, Department of Chemical Engineering and Chemistry, Eindhoven University of Technology, 5600 MB Eindhoven, \\ Netherlands \\ ${ }^{\mathrm{d}}$ Chemical Process Intensification, Department of Chemical Engineering and Chemistry, Eindhoven University of Technology, 5600 MB Eindhoven, Netherlands \\ e Otto-Schott Institute of Materials Research, Friedrich-Schiller-Universität Jena, Jena 07743, Germany
}

\section{A R T I C L E I N F O}

\section{Keywords:}

$\mathrm{V}_{90} \mathrm{Cr}_{5} \mathrm{Al}_{5}$

Hydrogen permeable membrane

Stability

\begin{abstract}
A B S T R A C T
Hydrogen permeable V-Cr-Al alloys have been designed based on the lattice matching principle. To elucidate alloying effects of $\mathrm{Cr}$ and $\mathrm{Al}$, the hydrogen solubility and hydrogen permeation flux have been characterized at temperatures between 523 and $673 \mathrm{~K} . \mathrm{V}_{90} \mathrm{Cr}_{5} \mathrm{Al}_{5}$ exhibits a highly reduced hydrogen solubility, which contributes to enhanced resistance towards hydrogen embrittlement, at the same time maintaining the high permeability as pure vanadium at $673 \mathrm{~K}$. The stability of the $\mathrm{V}_{90} \mathrm{Cr}_{5} \mathrm{Al}_{5}$ membrane during hydrogen permeation tests at several temperatures has been characterized: $\mathrm{V}_{90} \mathrm{Cr}_{5} \mathrm{Al}_{5}$ shows a constant hydrogen permeation flux up to $500 \mathrm{~h}$ at $573 \mathrm{~K}$. A small drop in permeation flux $(J \times d)$ by $4 \%$ was observed at $623 \mathrm{~K}$ after $500 \mathrm{~h}$, i.e. from $1.35 \times 10^{-4}$ to $1.30 \times 10^{-4} \mathrm{~mol} \mathrm{H}_{2} \mathrm{~m}^{-1} \mathrm{~s}^{-1}$. Serious degradation in the hydrogen permeation flux during the long-term test was observed at the temperatures above $673 \mathrm{~K}$. This is attributed to the formation of a new barrier layer caused by the interdiffusion between $\mathrm{Pd}$ and $\mathrm{V}_{90} \mathrm{Cr}_{5} \mathrm{Al}_{5}$.
\end{abstract}

\section{Introduction}

Fossil fuels such as coal and oil account for about $80 \%$ of the primary energy supply in the world, resulting in a strong impact on the environment especially concerning the emissions of carbon dioxide and thus the greenhouse effect. Hydrogen, as an environmental-friendly energy carrier, has drawn fast-growing attention since the last decade. For production of high purity $\mathrm{H}_{2}$ by separating and purifying $\mathrm{H}_{2}$ from a gas mixture, for example from hydrocarbon reforming gas which contains $\mathrm{CO}_{2}, \mathrm{CO}$ and so on besides $\mathrm{H}_{2}$, membrane separation is one promising hydrogen separation and purification technique and attracting increasing interest. Materials ranging from polymers to metallic alloys have been developed as effective hydrogen separation membrane materials [1-10]. Among them, dense ceramic mixed proton-electron conducting (MPEC) membranes, which separate hydrogen as protons instead of molecules [1-3], exhibit 100\% hydrogen selectivity with an infinite separation factor as the major advantage. Some dense MPEC ceramic membranes exhibit reasonable proton conductivity up to $900{ }^{\circ} \mathrm{C}$. However, overcoming the dilemma between the chemical stability and proton conductivity has been the main aim for high performance MPEC ceramic membranes. Dense metal membranes, such as Pd, $\mathrm{V}, \mathrm{Nb}$ and Ta or their alloys and amorphous alloys are effective in separating ultrapure $(5 \mathrm{~N}) \mathrm{H}_{2}$ from other gases at temperature ranging from 300 to $600{ }^{\circ} \mathrm{C}$ [4-10]. The hydrogen permeation through metal membranes proceeds via consequently adsorption and dissociation of $\mathrm{H}_{2}$ to the $\mathrm{H}$ atoms, solution in the metal, diffusion, and re-association of $\mathrm{H}$ atoms to $\mathrm{H}_{2}$ and desorption. At present, Pd-based membranes, either of pure Pd or Pd-based alloys, are widely used for the production of high purity hydrogen by hydrogen permeation and separation processes [4-8]. However, the high cost and limited working temperature are restricting their large-scale application. Decreasing the thickness of the Pd-based membranes and alloying of Pd with less costly elements e.g. $\mathrm{Ag}, \mathrm{Cu}$ and $\mathrm{Ni}$, are considered as effective strategies for development of Pd-based hydrogen permeation membranes. In addition, metals and

\footnotetext{
* Corresponding author at: School of Materials Science and Engineering, Harbin Institute of Technology, Harbin 150001, PR China (X. Li).

** Corresponding author.

E-mail addresses: lixz@suda.edu.cn (X. Li), dongmei.Liu@uni-jena.de (D. Liu).

${ }^{1}$ These authors contributed equally to this work.
} 
alloys of Group VB (Nb, V and Ta etc.), which are of body-centered cubic (bcc) structure and exhibit higher hydrogen permeability, are considered as promising alternatives [9-36].

Among those metals, $\mathrm{V}$ exhibits excellent hydrogen permeability and malleability but suffers from severe hydrogen embrittlement (HE) induced by excessive hydrogen absorption [11-27]. For preventing HE by reducing the hydrogen content, a ductile-to-brittle transition hydrogen concentration was proposed as a criterion defining the changes from ductile fracture to brittle fracture behavior [35]. The hydrogen concentration $0.2(\mathrm{H} / \mathrm{M})$ was proposed as the critical hydrogen concentration for pure V at $673 \mathrm{~K}$ [35]. Improved the resistance to HE via reducing the hydrogen solubility of V-based membranes has been achieved by alloying and by adjusting the microstructure. Developing multiphase V-based alloys, for example, V-Ti-Ni [13-15] and V-Cu [24], was proven successful in hindering HE induced failure of membranes. This results from the reduced hydrogen solubility and the buffering effect from the eutectic structure. However, the presence of the second phase in such alloys, for example, B2-TiNi or fcc-Cu, which exhibits negligible hydrogen permeation, also induced much reduced hydrogen permeability. The solid solution in bcc phase using $\mathrm{W}, \mathrm{Ni}, \mathrm{Al}$ and $\mathrm{Co}$ at the same time can prevent the formation of the second phase e.g. B2TiNi phase, which allows maintaining high hydrogen permeability while improving HE resistance [12,17,21-27]. However, reduced hydrogen diffusivity has been often found in combination with alloying, which comes from the lattice distortion after alloying [26]. By matching the lattice constant to the value of pure $\mathrm{V}$, alloying of $\mathrm{V}$ simultaneously with Fe which contracts the $\mathrm{V}$ lattice and $\mathrm{Al}$ which expands the $\mathrm{V}$ lattice contributed to good hydrogen permeability and enhanced resistance to HE [26]. This mainly results from the negligible change in lattice parameters of bcc-(V) matrix after bi-alloying using $\mathrm{Fe}$ and $\mathrm{Al}$, which contributes to much-reduced hydrogen solubility but with enhanced hydrogen diffusivity. The strategy, matching the lattice constant to the value of pure $\mathrm{V}$, originated from Ref. [26] sheds a light on the development of robust single-phase V-based alloys of high hydrogen permeability using the empirical theory of lattice size matching. As reported in previous work [12], solely alloying of $\mathrm{V}$ with $\mathrm{Cr}$ leads to increasing lattice parameters of bcc-(V) phase, and solely alloying of $\mathrm{V}$ with $\mathrm{Al}$ exhibits the opposite trend. Hence, a comparable lattice parameter as that of pure $\mathrm{V}$ will probably occur after proper simultaneous alloying with $\mathrm{Cr}$ and $\mathrm{Al}$, similar as that occured to V-Fe-Al system [26]. In the present work, bi-alloying of $\mathrm{V}$ using $\mathrm{Cr}$ and $\mathrm{Al}$ was performed aiming for simultaneous improvement in HE resistance and hydrogen permeability.

In addition to the high permeability and HE resistance, another essential property of metal membranes is the stability at elevated operating temperatures and pressures. Lundin et al. [37] reported the depression of the hydrogen flux through Pd membranes at $623 \mathrm{~K}$ and $673 \mathrm{~K}$, which was induced by the morphological changes of the Pd surface that affected its hydrogen absorption rate. Besides, the interdiffusion between the membrane and the porous stainless steel support was reported inducing permeability decline of Pd-Cu alloy membranes [38]. Dolan et al. [39] reported the permeability decay of Pd-coated tubular V membranes at $573 \mathrm{~K}$ and $613 \mathrm{~K}$. Similar permeability degradation has been observed in other Pd-coated non-Pd alloy membranes [40-50]. The decrease in permeability is usually induced by the following reasons: the surface rearrangement of the Pd layer, the interdiffusion between the Pd layer and support components, and mass transfer limitations at the upstream side. For the plate-type membranes, especially for V-based membranes, the focus is usually on high permeability and less attention is paid to stability. Therefore, the development of appropriate V-based hydrogen separation membranes still requires further research to enhance the permeability and stability. In the present work, the stability of V-Cr-Al alloy membranes was characterized, and the decay mechanism of hydrogen permeability was discussed.

\section{Experimental}

\subsection{Sample preparation and microstructure characterization}

As-cast ingots of pure $\mathrm{V}, \mathrm{V}_{95} \mathrm{Cr}_{5}, \mathrm{~V}_{95} \mathrm{Al}_{5}, \mathrm{~V}_{95} \mathrm{Cr}_{5} \mathrm{Al}_{5}$ and $\mathrm{V}_{85} \mathrm{Cr}_{10} \mathrm{Al}_{5}$ alloys of $30 \mathrm{~g}$ were prepared by arc melting under a pure argon atmosphere from pure $\mathrm{V}, \mathrm{Cr}$ and $\mathrm{Al}$ ( $\geq 99.9 \%$ purity), during which a water-cooled segmented cooper crucible was used. After loading the pure elements into the copper crucible, the chamber was first evacuated till $8 \times 10^{-3} \mathrm{~Pa}$ and charged with high purity Ar $(9 \mathrm{~N})$. The elements were then melted using a non-consumable tungsten electrode with a maximum direct current of 500 A. Strong convection was imposed during the melting and solidification process. In combination, the melting and solidification process was performed at least 5 times for each ingot to reach macro-scale homogeneity.

For characterizing the hydrogen solubility and permeability of the alloys, disks of $16 \mathrm{~mm}$ in diameter and $0.8 \mathrm{~mm}$ in thickness were cut from the as-cast ingots by a spark erosion wire-cutting machine. Grinding was performed to get rid of the contamination until the thickness was $0.6 \mathrm{~mm}$, followed by the final polishing using liquid suspension composed of $\mathrm{Al}_{2} \mathrm{O}_{3}$ particle of $0.5 \mu \mathrm{m}$ in diameter. Each side of the disk was coated with a Pd layer by electroless plating. Pd coating layers of $900 \mathrm{~nm}$ in thickness were applied to promote $\mathrm{H}_{2}$ dissociation and recombination and also to avoid oxidation. Before the electroless plating, the surfaces of the membrane were activated in a $\mathrm{PdCl}_{2}$ and $\mathrm{HCl}$ solution at room temperature. This step lasted $20 \mathrm{~min}$ until the surface of the disk lost the metallic luster and became dark. Then electroless plating in a special ethylene diamine tetraacetic acid (EDTA)-based solution was performed at $323 \mathrm{~K}$. More details can be found in previous work [51].

The constituent phase of the membranes before and after hydrogen permeation tests were characterized by X-ray diffraction analysis (XRDRigaku MiniFlex 600) with the $\mathrm{Cu}$-Ka radiation by the step rate of $0.1^{\circ}$ \% min (with the step size of $0.02^{\circ}$ ) in $2 \theta$ range of $20-100^{\circ}$. The microstructure of the membranes was characterized using a scanning electron microscope (SEM-FEI Quanta 250F) equipped with energy diffraction X-ray (EDX) analysis. An accelerating voltage of $15 \mathrm{kV}$ was used for the images and the EDX analysis. For characterizing the interdiffusion between Pd and V after long-term hydrogen permeation tests, the Pd/V/ Pd membrane was clamped tightly by a house made metallic holder and then the cross section was grinded and polished. Linear EDX analysis across the $\mathrm{Pd} / \mathrm{V}$ interface was performed with a step interval of $20 \mathrm{~nm}$.

\subsection{Hydrogen solubility and permeability}

The hydrogen solubility of as-cast $\mathrm{V}, \mathrm{V}_{95} \mathrm{Cr}_{5}, \mathrm{~V}_{95} \mathrm{Al}_{5}, \mathrm{~V}_{95} \mathrm{Cr}_{5} \mathrm{Al}_{5}$ and $\mathrm{V}_{85} \mathrm{Cr}_{10} \mathrm{Al}_{5}$ alloys was measured using a Sieverts-type apparatus [24] with hydrogen pressure ranging from 0.01 up to $0.80 \mathrm{MPa}$ at temperatures ranging from 523 to $673 \mathrm{~K}$. The amount of absorbed hydrogen was calculated based on the measured pressure drop in a constant inner volume chamber. The hydrogen permeable properties of the $\mathrm{V}_{95} \mathrm{Cr}_{5} \mathrm{Al}_{5}$ and $\mathrm{V}_{85} \mathrm{Cr}_{10} \mathrm{Al}_{5}$ membranes under pure hydrogen atmosphere were characterized using a gas permeation apparatus as in Ref. [51]. The membrane was sealed by copper gaskets during the permeation test. Before the hydrogen permeation tests, both the feed side (upstream side) and permeate side (downstream side) of the membrane were first swept using a continuous $\mathrm{N}_{2}$ flow introduced to the upstream side. Then the membrane was heated to the desired measuring temperature under pure $\mathrm{N}_{2}$. For checking the intact of the membrane, pure $\mathrm{N}_{2}$ up to 0.7 MPa was introduced to the upstream side, and at the same time the $\mathrm{N}_{2}$ at the downstream side was kept at a pressure of $0.1 \mathrm{MPa}$. In case of detected $\mathrm{N}_{2}$ flow by the flow meter, which indicates the presence of cracks or pores in the membrane, a new membrane will be used for hydorgen permeation test. Before each hydrogen permeation test, an air activation step was performed to promote the dissociation and absorption of hydrogen [52]. Then, the feed side and the permeate side 
were evacuated. The feed side was charged by high purity $\mathrm{H}_{2}$ with upstream pressure $\left(P_{\mathrm{u}}\right)$ ranging from 0.15 to $0.70 \mathrm{MPa}$. At the same time, the hydrogen pressure at the downstream side $\left(P_{\mathrm{d}}\right)$ was kept at $0.10 \mathrm{MPa}$. The hydrogen flux, $J$, through the membrane was measured using a hydrogen flow meter. Intervals of $15 \mathrm{~min}$ were employed during measurements to ensure a steady-state hydrogen flux through the membrane. Hydrogen permeation tests for the long duration were performed to characterize the stability of the membranes, where the upstream pressure was kept at $0.7 \mathrm{MPa}$ during the whole test.

The hydrogen solubility of the alloy, $C$, is normally expressed as [9],

$C=K \cdot P^{0.5}$

where $K$ is the hydrogen solubility coefficient.

The steady-state hydrogen permeable flux $(J)$ through the membranes is calculated using the first Fick's law,

$J=-D \times \frac{\Delta C}{L}$

where $D$ is the hydrogen diffusion coefficient, and $L$ is the thickness of the membrane.

Combining Eqs. (1) and (2), the steady-state hydrogen permeable flux $(J)$ can be described as follows:

$J=\frac{D \times K\left(P_{u}^{0.5}-P_{d}^{0.5}\right)}{L}=\frac{\Phi \times \Delta P^{0.5}}{L}$

where $P_{\mathrm{u}}$ and $P_{\mathrm{d}}$ are the hydrogen pressure at the upstream and downstream side, and $\Phi$ is the hydrogen permeability. This implies that the hydrogen permeability, $\Phi$, of the present alloys in a hydrogen pressure range at a certain temperature can be calculated based on the measured hydrogen solubility and hydrogen permeable flux.

\section{Results and discussion}

3.1. Microstructure and phase constituent of as-cast $V_{95-x} C r_{x} A l_{5}(x=0,5$, 10) alloys

Fig. 1 shows the XRD patterns of the as-cast ingots of $\mathrm{V}, \mathrm{V}_{95} \mathrm{Al}_{5}$, $\mathrm{V}_{95} \mathrm{Cr}_{5}, \mathrm{~V}_{90} \mathrm{Cr}_{5} \mathrm{Al}_{5}$ and $\mathrm{V}_{85} \mathrm{Cr}_{10} \mathrm{Al}_{5}$ alloys before the hydrogen permeation tests. Only diffraction peaks corresponding to bcc-V phase were observed, and no secondary phases were detected in all the samples. Single-phase microstructure was also confirmed by backscattered electron (BSE), as shown by the inset image in Fig. 1. This is consistent with the fact that $\mathrm{V}$ and $\mathrm{Cr}$ exhibit unlimited mutual solubility across the entire system [53], and that $\mathrm{V}$ exhibits a high solid solubility of $\mathrm{Al}$

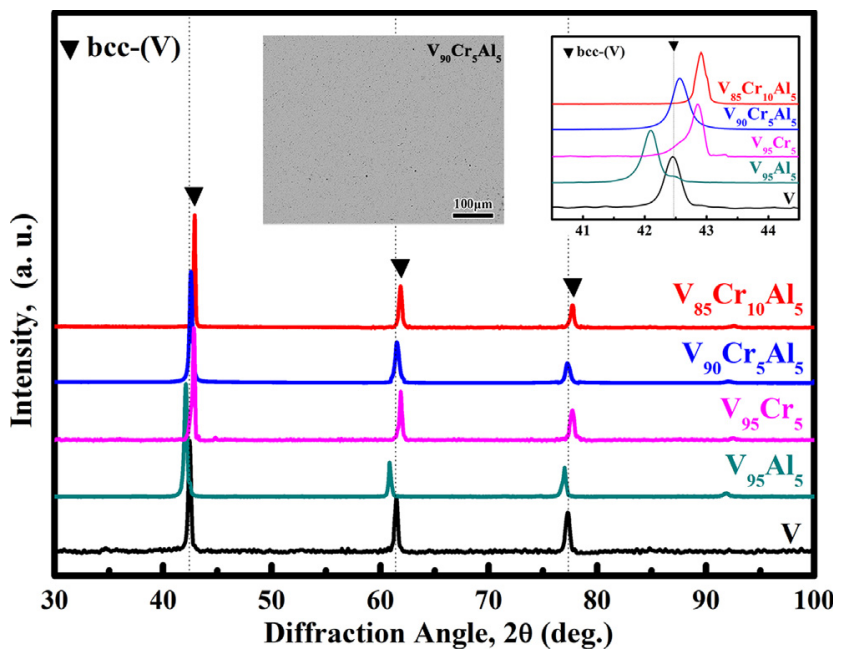

Fig. 1. XRD patterns of as-cast pure $\mathrm{V}$ and $\mathrm{V}-\mathrm{Cr}-\mathrm{Al}$ alloys. The inserted pictures show the microstructure of as-cast $\mathrm{V}_{90} \mathrm{Cr}_{5} \mathrm{Al}_{5}$ alloy and the local magnified XRD patterns highlighting the shift of the main peak. up to $\sim 54$ at $\%$ [54]. The same brightness over the whole sample indicates the homogeneous distribution of $\mathrm{Al}$ and $\mathrm{Cr}$ in the bcc phase. $\mathrm{A}$ shift of diffraction peaks to lower angles was observed for $\mathrm{V}_{95} \mathrm{Al}_{5}$, indicating an increase in the lattice parameter of bcc-(V) after $\mathrm{Al}$ alloying, as shown in the inset local magnification of the XRD patterns in Fig. 1. The opposite trend was observed beyond a $\mathrm{Cr}$ alloy content of 5\%, indicating a decrease in the lattice parameter of bcc-(V). After simultaneous alloying using $\mathrm{Al}$ and $\mathrm{Cr}$ of $5 \mathrm{at} \%$, the $\mathrm{V}_{90} \mathrm{Cr}_{5} \mathrm{Al}_{5}$ alloy exhibits nearly identical diffraction pattern as pure $\mathrm{V}$, indicating a negligible change in the lattice parameter. However, with the further increase of $\mathrm{Cr}$ content, i.e. $\mathrm{V}_{85} \mathrm{Cr}_{10} \mathrm{Al}_{5}$ alloy, the location of the diffraction peaks shifts to higher angles in comparison with pure $\mathrm{V}$, similar to those of $\mathrm{V}_{95} \mathrm{Cr}_{5}$. The calculated lattice parameters of $\mathrm{V}$-Cr-Al alloys follow the trend: pure V $(3.0376 \AA)>\mathrm{V}_{90} \mathrm{Cr}_{5} \mathrm{Al}_{5}(3.0330 \AA)>\mathrm{V}_{85} \mathrm{Cr}_{10} \mathrm{Al}_{5}$ (3.0215 $\AA$ ). Such a shift is induced by the interactive effect of $\mathrm{Cr}$ and $\mathrm{Al}$ dissolved into the $\mathrm{V}$ lattice. According to the lattice matching principle [26], $\mathrm{V}_{90} \mathrm{Cr}_{5} \mathrm{Al}_{5}$ is supposed to exhibit comparable hydrogen diffusivity as pure $\mathrm{V}$ resulting from nearly the same lattice parameter.

\subsection{Hydrogen solubility of as-cast $V_{95-x} C r_{x} A l_{5}(x=0,5,10)$ alloys}

The pressure-composition-isotherms (PCT) curves of as-cast V-Cr-Al alloys at $673 \mathrm{~K}$ are shown in Fig. 2(a). The PCT curve of pure $\mathrm{V}$ in the present work is close to that from the literature [12]. After alloying using $\mathrm{Al} / \mathrm{Cr}$, a decrease in the hydrogen solubility was observed, as shown in Fig. 2(a). $\mathrm{V}_{95} \mathrm{Cr}_{5}$ and $\mathrm{V}_{95} \mathrm{Al}_{5}$ exhibited similar hydrogen solubility. However, after bi-alloying using $\mathrm{Cr}$ and $\mathrm{Al}$ up to 5 at\%, i.e. $\mathrm{V}_{90} \mathrm{Cr}_{5} \mathrm{Al}_{5}$, a large decrease in the hydrogen solubility in comparison with $\mathrm{V}_{95} \mathrm{Cr}_{5}$ was observed. Similarly, $\mathrm{V}_{85} \mathrm{Cr}_{10} \mathrm{Al}_{5}$ showed a further decrease in the hydrogen solubility. When the pressure above $0.1 \mathrm{MPa}$, the hydrogen solubility of $\mathrm{V}_{90} \mathrm{Cr}_{5} \mathrm{Al}_{5}$ is close to the value of the $\mathrm{V}_{90} \mathrm{Fe}_{5} \mathrm{Al}_{5}$ [55]. The observed reduced hydrogen solubility in comparison with pure $\mathrm{V}$ after alloying with $\mathrm{Al}$ and $\mathrm{Cr}$ is consistent with previous work [12,17], that $\mathrm{Al} / \mathrm{Cr}$ alloying in $\mathrm{V}$ is prone to inhibit the hydrogen absorption. The decreased hydrogen solubility is due to the change in the electronic structures and strain energy of dissolved hydrogen, which results from the existence of interstitial sites of a different size in the bcc matrix. The concept of site blocking [56] cannot well explain the highly reduced hydrogen solubility of $\mathrm{V}_{90} \mathrm{Cr}_{5} \mathrm{Al}_{5}$, because $\mathrm{V}_{90} \mathrm{Cr}_{5} \mathrm{Al}_{5}$ has similar lattice parameters as that of pure $\mathrm{V}$. It can be concluded that other than the content of the alloying elements, the interactive effects of those elements, for example, the mixing rule $[26,56]$, plays a critical role.

The PCT curves of the as-cast $\mathrm{V}_{90} \mathrm{Cr}_{5} \mathrm{Al}_{5}$ and $\mathrm{V}_{85} \mathrm{Cr}_{10} \mathrm{Al}_{5}$ at temperatures between 523 and $673 \mathrm{~K}$ are shown in Fig. 2(b). The hydrogen solubility of the two alloys increases with decreasing temperature under a certain $\mathrm{H}_{2}$ pressure. This is consistent with the exothermic nature of hydrogen solubility of group $\mathrm{V}$ metals. $\mathrm{V}_{85} \mathrm{Cr}_{10} \mathrm{Al}_{5}$ exhibits lower hydrogen solubilities than $\mathrm{V}_{90} \mathrm{Cr}_{5} \mathrm{Al}_{5}$ under the same pressure and temperature. For $\mathrm{H}_{2}$ pressures above $0.1 \mathrm{MPa}$, deviation of $P C T$ curves $\left(P^{0.5}\right.$ $\sim r(H / M)$ ) from the linear relationship, i.e. the Sieverts' law, was detected for all the alloys, which is due to the change of elastic and electronic properties of $\mathrm{V}$ and the effect of the absorption of interstitial hydrogen atoms [24,55,57-59]. The nearly linear relationship between the hydrogen solubility, $r(H / M)$ and $P^{0.5}$ only holds when the $\mathrm{H}_{2}$ pressure is lower than $0.1 \mathrm{MPa}$. This is similar to the previous work on the V-based alloy membranes [19,60-63].

\subsection{Hydrogen permeability of $V_{95-x} C_{x} A l_{5}(x=5,10)$ membranes}

A normalized hydrogen permeation flux $J \times d$ (where $J$ is the hydrogen permeation flux measured during the test, and $d$ is the thickness of the membrane) of $\mathrm{V}_{90} \mathrm{Cr}_{5} \mathrm{Al}_{5}$ and $\mathrm{V}_{85} \mathrm{Cr}_{10} \mathrm{Al}_{5}$ alloy membranes is characterized, as shown in Fig. 3(a). A nearly linear relationship between the normalized hydrogen permeation flux and $\Delta P^{0.5}\left(=P_{u}^{0.5}-P_{d}^{0.5}\right)$ is observed for temperatures ranging from $523 \mathrm{~K}$ to 

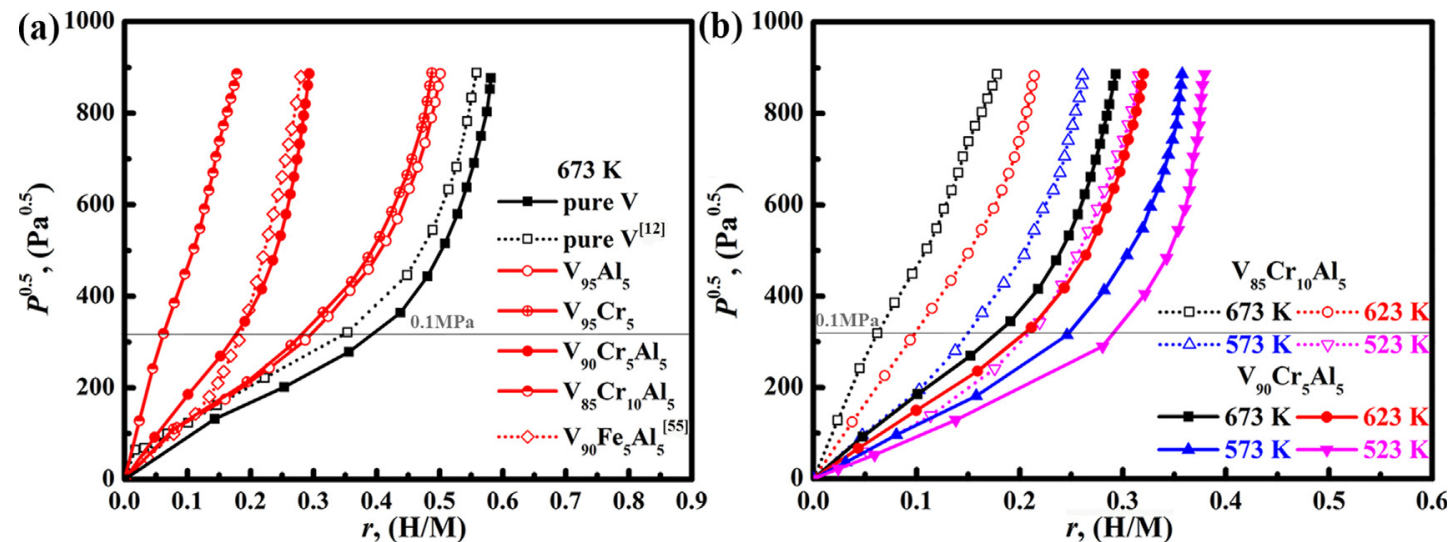

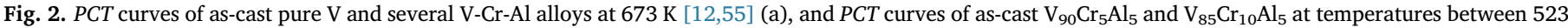
and $673 \mathrm{~K} \mathrm{(b).}$

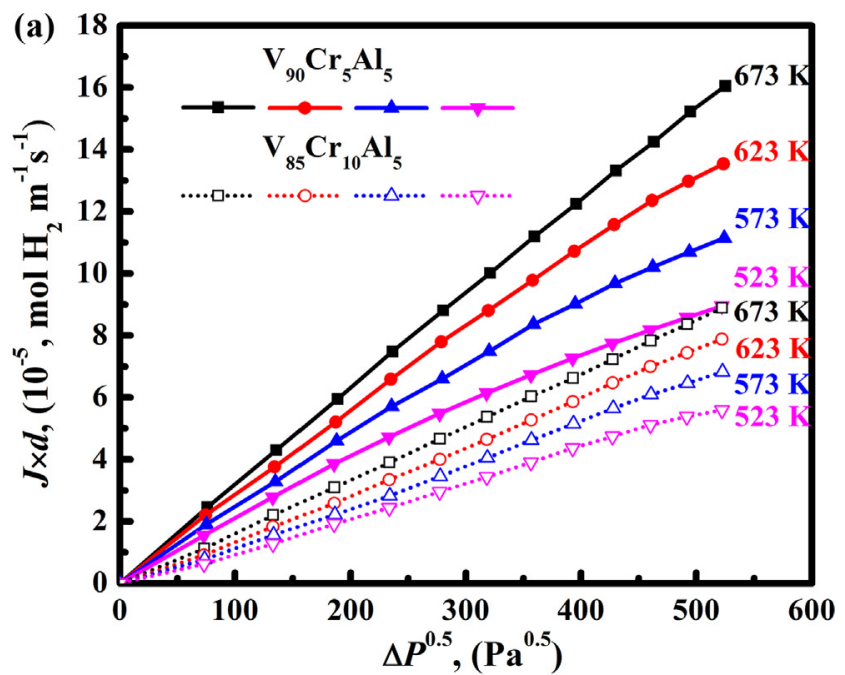

the curves can be regarded as the hydrogen permeability. Overall, $\mathrm{V}_{90} \mathrm{Cr}_{5} \mathrm{Al}_{5}$ exhibits a higher hydrogen permeability than $\mathrm{V}_{85} \mathrm{Cr}_{10} \mathrm{Al}_{5}$ at the same temperature. For each membrane, the hydrogen permeability and the hydrogen permeation flux increase with increasing temperature. A normalized hydrogen permeation flux of $1.61 \times 10^{-4} \mathrm{~mol} \mathrm{H}_{2}$ $\mathrm{m}^{-1} \mathrm{~s}^{-1}$ was reached for the $\mathrm{V}_{90} \mathrm{Cr}_{5} \mathrm{Al}_{5}$ membrane at $673 \mathrm{~K}$ with a $\mathrm{H}_{2}$ pressure drop of $0.6 \mathrm{MPa}$. This is nearly the same as the reported $J \times d$ of a $\mathrm{V}_{95} \mathrm{Cr}_{5}$ alloy membrane at similar feed pressure [12]. Keeping the lower hydrogen solubility of $\mathrm{V}_{90} \mathrm{Cr}_{5} \mathrm{Al}_{5}$ comparable to $\mathrm{V}_{95} \mathrm{Cr}_{5}$ in mind, bi-alloying with $\mathrm{Cr}$ and $\mathrm{Al}$ is advantageous for improved mechanical stability while maintaining the same hydrogen permeability.

A comparison of the hydrogen permeability between as-cast $\mathrm{V}_{90} \mathrm{Cr}_{5} \mathrm{Al}_{5}, \mathrm{~V}_{85} \mathrm{Cr}_{10} \mathrm{Al}_{5}$ and other V-based alloy membranes from literature $[12,15,26,41]$ is shown in Fig. $3(\mathrm{~b}) . \mathrm{V}_{90} \mathrm{Cr}_{5} \mathrm{Al}_{5}$ exhibits the highest hydrogen permeability among the reported V-based alloys $[12,15,26,41]$, for example $3.05 \times 10^{-7} \mathrm{~mol} \mathrm{~m}^{-1} \mathrm{~s}^{-1} \mathrm{~Pa}^{-0.5}$ at $673 \mathrm{~K}$. This value is one order higher than that of pure Pd $\left(1.6 \times 10^{-8} \mathrm{~mol}\right.$ $\mathrm{m}^{-1} \mathrm{~s}^{-1} \mathrm{~Pa}^{-0.5}$ ) at the same temperature. Therefore, for reaching the same hydrogen permeation flux, a $\mathrm{V}_{90} \mathrm{Cr}_{5} \mathrm{Al}_{5}$ membrane can be 16 times thicker than a pure Pd membrane. $\mathrm{V}_{85} \mathrm{Cr}_{10} \mathrm{Al}$ exhibits lower hydrogen permeability than that of $\mathrm{V}_{90} \mathrm{Cr}_{5} \mathrm{Al}_{5}$, which is still higher than the reported value from Ref. [51]. This may result from the air treatment before the permeation test.

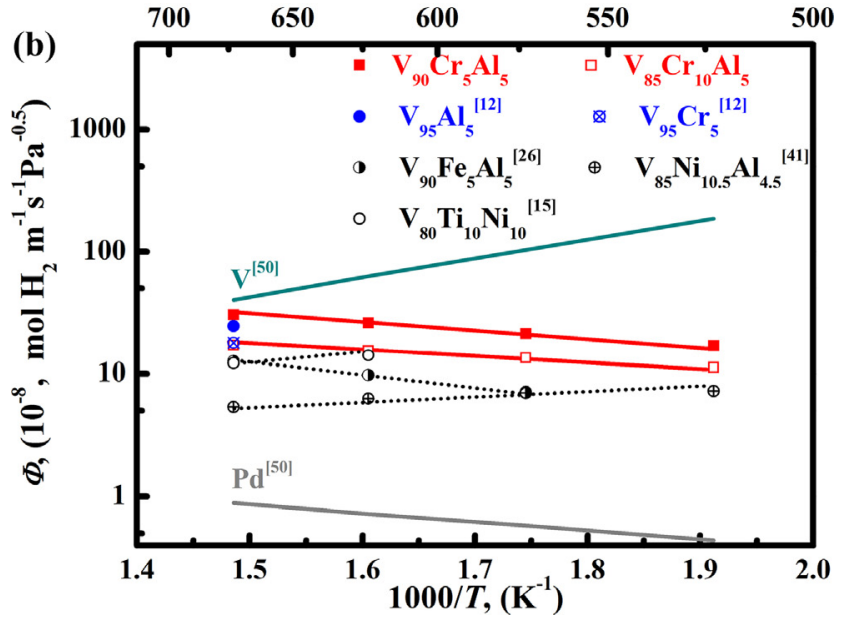

Fig. 3. Dependence of the normalized hydrogen permeation flux $(J \times d)$ of ascast $\mathrm{V}_{90} \mathrm{Cr}_{5} \mathrm{Al}_{5}$ and $\mathrm{V}_{85} \mathrm{Cr}_{10} \mathrm{Al}_{5}$ membranes on $\Delta P^{0.5}=P_{u}^{0.5}-P_{d}^{0.5}$ (a); hydrogen permeability of pure V, Pd [50] and different V-based alloy membranes $[12,15,26,41]$ (b).

$673 \mathrm{~K}$, during which $P_{\mathrm{d}}$ was kept at $0.1 \mathrm{MPa}$. A small deviation from linearity was discerned for higher upstream $\mathrm{H}_{2}$ pressures, especially for $\mathrm{V}_{90} \mathrm{Cr}_{5} \mathrm{Al}_{5}$ at lower temperatures. This indicates that bulk diffusion through the $\mathrm{V}_{90} \mathrm{Cr}_{5} \mathrm{Al}_{5}$ alloy membrane is the rate limiting step, although Sieverts' law does not hold at higher $\mathrm{H}_{2}$ pressures. The slope of

\subsection{Hydrogen diffusion coefficient of as-cast $V_{95-x} C r_{x} A l_{5}(x=5,10)$ alloys}

The apparent diffusion coefficient has been recognized as a pseudovalue [63] because of the effect of the infiltration distance of hydrogen atom throughout the membranes. Extensive efforts have been done to modify the "Arrhenius" equation of diffusion by introducing a concentration-independent diffusion coefficient $D_{H}^{*}$. Nevertheless, the concentration-dependent diffusion coefficient $D$ from the classical Fick's first law can still provide a criterion for evaluating the diffusion of hydrogen throughout the membranes. Based on the experimentally characterized dependence of hydrogen solubility on hydrogen pressure $P^{0.5}$ (Fig. 2), the hydrogen solubility difference between the upstream side (0.1 to $0.7 \mathrm{MPa}$ ) and downstream (maintained as 0.1 MPa) side $(\Delta C)$ was obtained. Correlating the dependence of hydrogen flux on hydrogen pressure (Fig. 3), the concentration-dependent diffusion coefficient $D$ was calculated based on Eq. (2). The $D$ values of as-cast $\mathrm{V}_{90} \mathrm{Cr}_{5} \mathrm{Al}_{5}$ and $\mathrm{V}_{85} \mathrm{Cr}_{10} \mathrm{Al}_{5}$ membranes at $523-673 \mathrm{~K}$ was be calculated, which are shown in Fig. 4(a) and (b). An increasing trend of the calculated hydrogen diffusion coefficients $(D)$ on the hydrogen solubility is found for each temperature, which is consistent with previous studies on V-based alloy membranes $[12,58] . \mathrm{V}_{85} \mathrm{Cr}_{10} \mathrm{Al}_{5}$ exhibits lower $D$ values than $\mathrm{V}_{90} \mathrm{Cr}_{5} \mathrm{Al}_{5}$ under the same condition. This indicates that $\mathrm{Cr}$ 

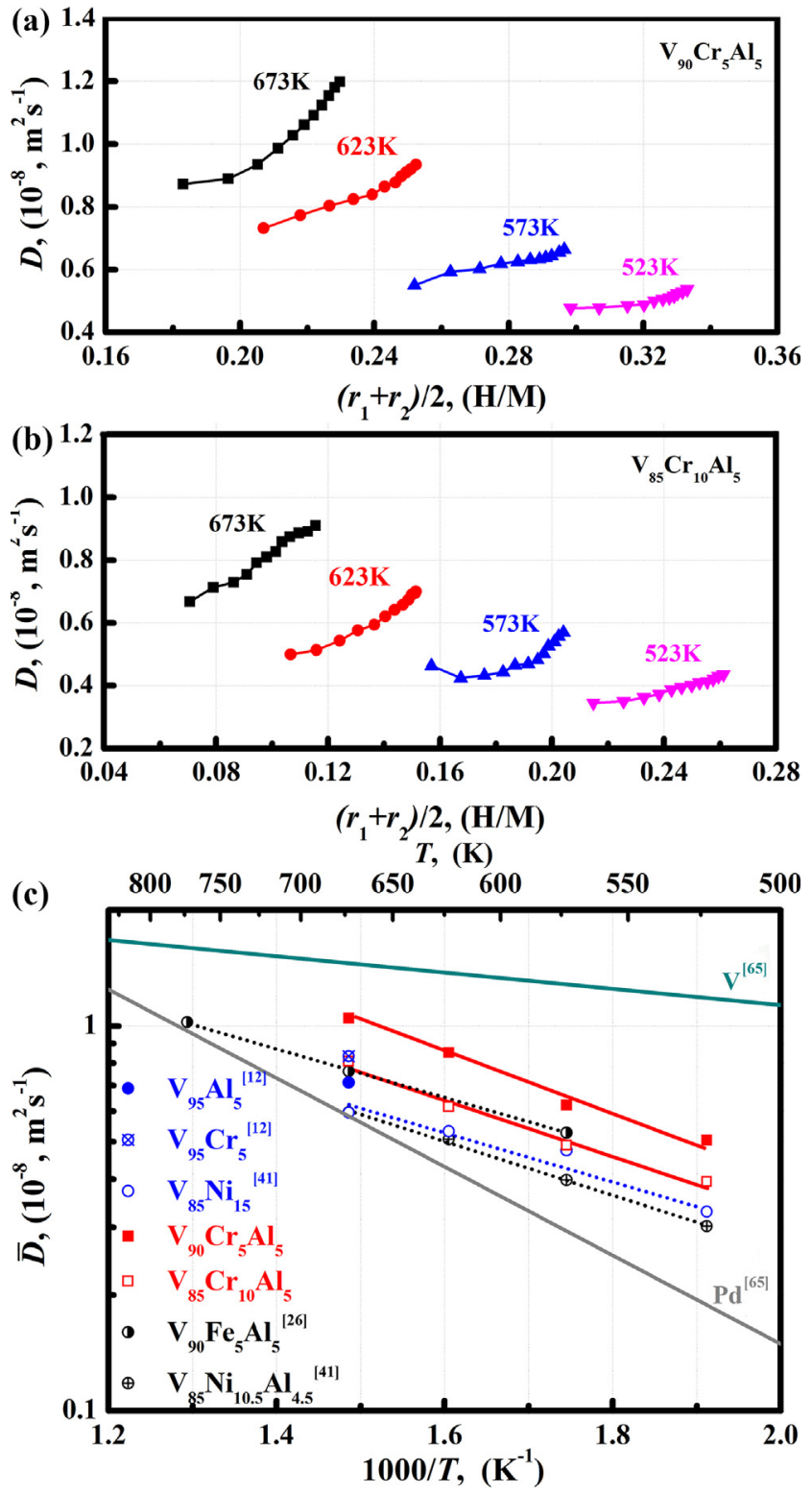

Fig. 4. Dependence of the diffusion coefficients on hydrogen concentration for $\mathrm{V}_{90} \mathrm{Cr}_{5} \mathrm{Al}_{5}$ (a) and $\mathrm{V}_{85} \mathrm{Cr}_{10} \mathrm{Al}_{5}$ (b) membranes at temperatures between 523 and $673 \mathrm{~K}$, and a comparison of the average hydrogen diffusion coefficients $(\bar{D})$ of several V-based alloy membranes $[12,26,41,65]$ (c).

acts as defects in the substrate alloy $\mathrm{V}$, which affects the distribution of hydrogen potential in $\mathrm{V}$ due to the change in the distribution of site energy and the jumping rate of hydrogen in $\mathrm{V}$ [64]. To compare the membranes of different alloys, the average hydrogen diffusion coefficients, $\bar{D}$, which is the average value of the hydrogen diffusion coefficients of $\mathrm{V}_{85} \mathrm{Cr}_{10} \mathrm{Al}_{5}$ and $\mathrm{V}_{90} \mathrm{Cr}_{5} \mathrm{Al}_{5}$ membranes at a certain temperature (Fig. 4(a) and (b)), are illustrated in Fig. 4(c). An Arrhenius relationship between the average hydrogen diffusion coefficients $(\bar{D})$ and the temperature in the temperature range $523-673 \mathrm{~K}$ is confirmed. The average hydrogen diffusion coefficients of the V-based alloys fall between the values of pure $\mathrm{V}$ and pure $\mathrm{Pd}$, and the $\mathrm{V}_{90} \mathrm{Cr}_{5} \mathrm{Al}_{5}$ exhibits the highest $\bar{D}$ value among listed membranes in the temperature range 523-673 K.

\subsection{Stability of hydrogen permeation flux of $V_{90} \mathrm{Cr}_{5} \mathrm{Al}_{5}$ membranes}

Hydrogen permeation tests of as-cast $\mathrm{V}_{90} \mathrm{Cr}_{5} \mathrm{Al}_{5}$ membrane up to $500 \mathrm{~h}$ were performed in the temperature range between 573 and $753 \mathrm{~K}$, during which the $\mathrm{H}_{2}$ pressure at the upstream and downstream
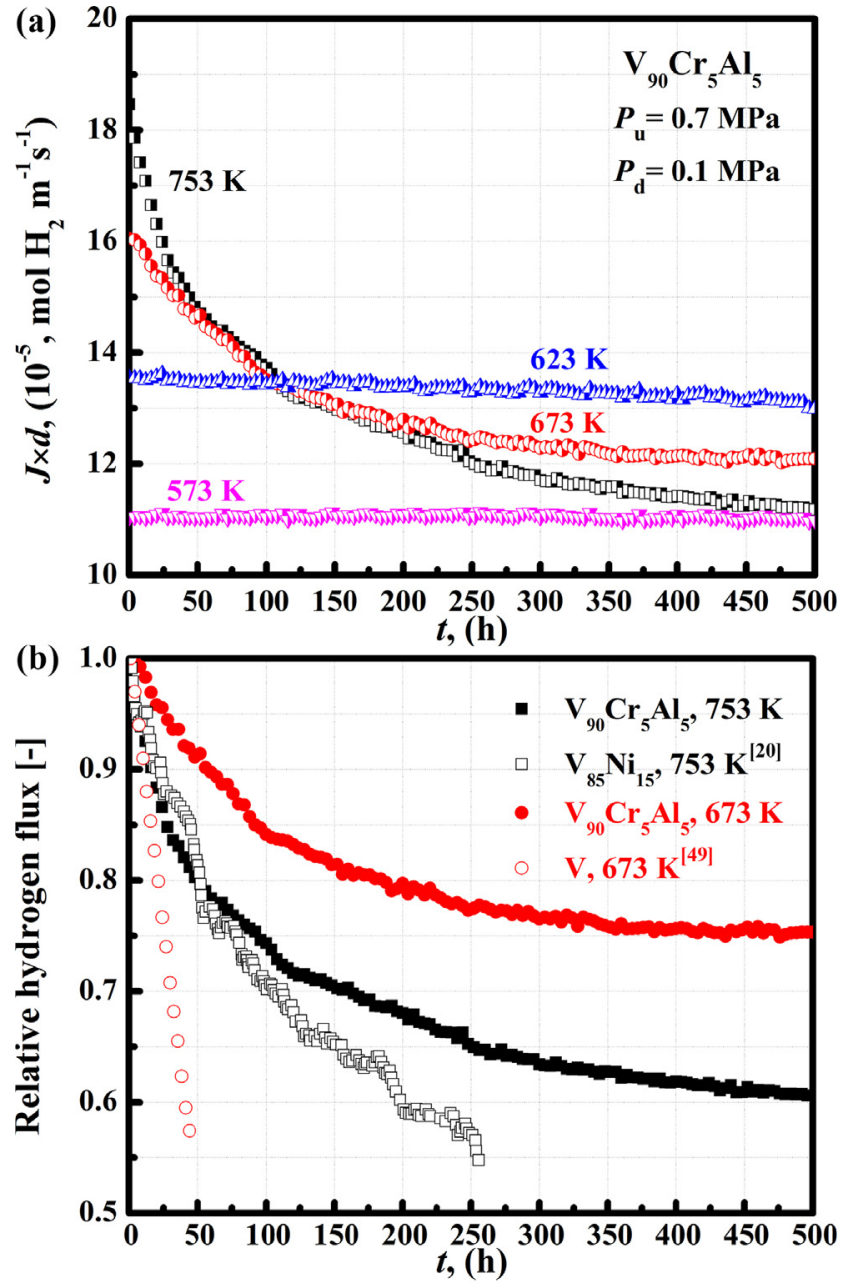

Fig. 5. Normalized hydrogen permeable flux of $\mathrm{V}_{90} \mathrm{Cr}_{5} \mathrm{Al}_{5}$ membrane during the long-term test at 573-753 K (a); a comparison of the degradation in hydrogen permeation flux of some V-based alloy membranes [20,49] (b).

side was kept at 0.7 MPa and 0.1 MPa, respectively. The measured hydrogen permeation flux is illustrated in Fig. 5(a). At 673 and $753 \mathrm{~K}$, a fast decrease in the hydrogen permeation flux during the long-term test was observed. At $753 \mathrm{~K}$, the normalized hydrogen permeation flux $(J \times d)$ decreases dramatically from $1.85 \times 10^{-4}$ to $1.10 \times 10^{-4} \mathrm{~mol}$ $\mathrm{H}_{2} \mathrm{~m}^{-1} \mathrm{~s}^{-1}$, i.e. a reduction of $\sim 38 \%$. At $673 \mathrm{~K}, J \times d$ decreases from $1.6 \times 10^{-4}$ to $1.2 \times 10^{-4} \mathrm{~mol} \mathrm{H}_{2} \mathrm{~m}^{-1} \mathrm{~s}^{-1}$ corresponding to a reduction of $25 \%$. In comparison, only a slight decrease of $4 \%$ in the hydrogen permeation flux up to $500 \mathrm{~h}$ is observed at $623 \mathrm{~K}$, and the hydrogen permeation flux remains constant at $573 \mathrm{~K}$. The decreasing tendency of the as-cast $\mathrm{V}_{90} \mathrm{Cr}_{5} \mathrm{Al}_{5}$ membrane during the long-term test is illustrated in Fig. 5(b), along with several V-based alloy membranes $[20,49]$. In comparison with pure $\mathrm{V}$ [49], the decreasing rate of the rest alloys in the hydrogen permeation flux at $673 \mathrm{~K}$ is much lower. This less deleterious effect is supposed to come from the reduced diffusion coefficient of $\mathrm{Pd}$ in $\mathrm{V}$ matrix after alloying using $\mathrm{Cr}$ and $\mathrm{Al}$, or segregation of some alloying element(s) at the grain boundary, which further hinders the fast diffusion along the grain boundaries [20]. With the temperature increase up to $753 \mathrm{~K}$, despite the fast degradation of the hydrogen permeation flux, the degradation rate of the $\mathrm{V}_{90} \mathrm{Cr}_{5} \mathrm{Al}_{5}$ membrane is still slower than that of the $\mathrm{V}_{85} \mathrm{Ni}_{15}$ membrane at $753 \mathrm{~K}$ and that of pure $\mathrm{V}$ at $673 \mathrm{~K}$.

\subsection{Interdiffusion between $P d$ and $V_{90} \mathrm{Cr}_{5} \mathrm{Al}_{5}$ substrate}

Considering that the thickness of the Pd catalytic layer in the 

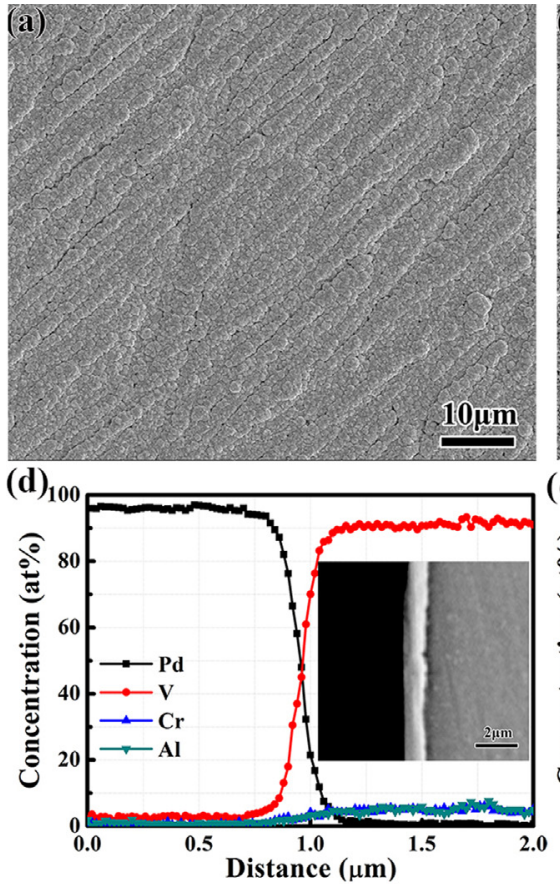
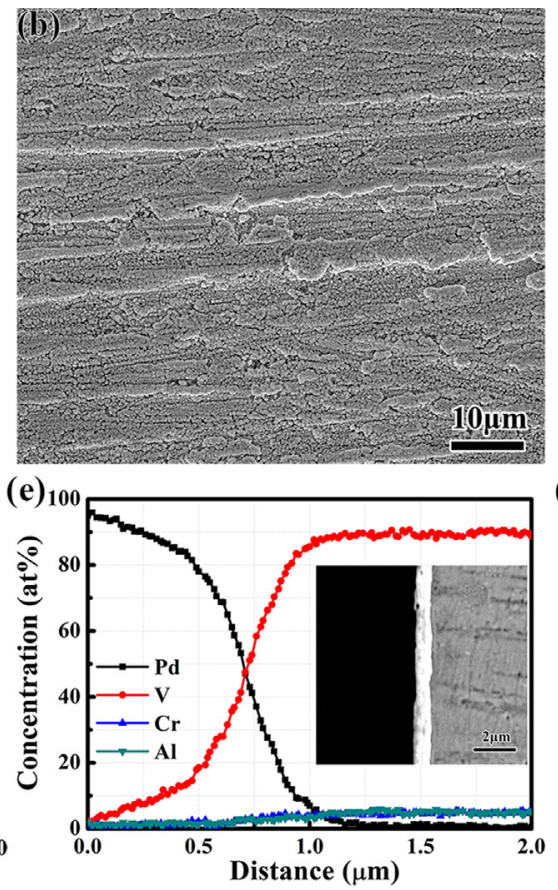
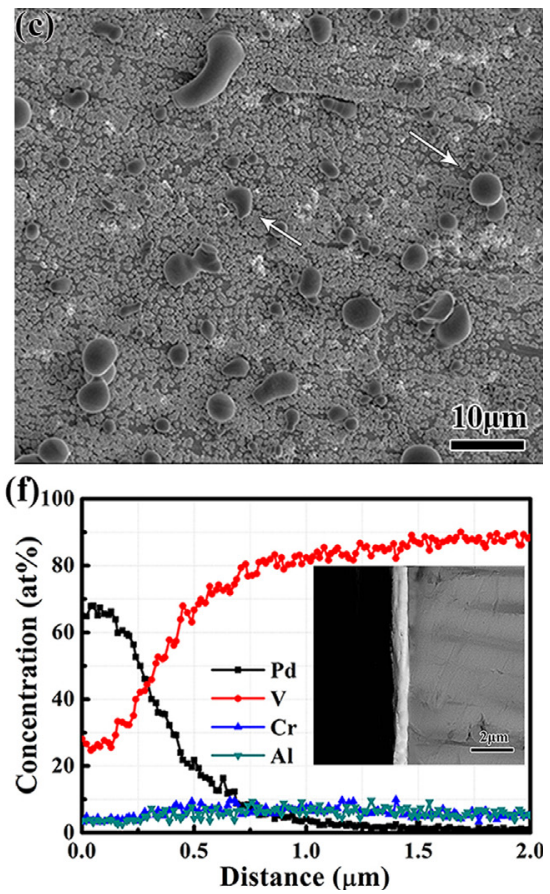

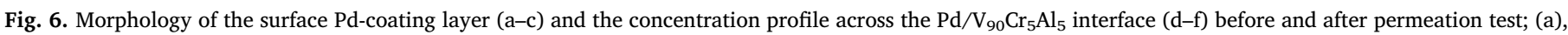
(d) pre-test, (b), (e) $623 \mathrm{~K} / 500 \mathrm{~h}$, (c), (f) $673 \mathrm{~K} / 500 \mathrm{~h}$.

present work is $900 \mathrm{~nm}$, the rate of hydrogen transport through the Pd layer is supposed to be controlled by the surface reaction, i.e. dissociation and association of $\mathrm{H}_{2}$ molecules at the upstream and downstream sides $[6,24]$. The rate limiting step for the hydrogen permeation through the $\mathrm{Pd} / \mathrm{V} / \mathrm{Pd}$ membrane is the bulk diffusion through the Vbased membrane material. According to previous work on V-Pd alloys $[40,58]$, V-Pd alloys with Pd content about 10 at $\%$ exhibit lower hydrogen permeability than that of pure $\mathrm{V}$ but higher than that of pure Pd [50]. For example, V-10 at\%Pd alloy exhibits a hydrogen permeability of $3.86 \times 10^{-8} \mathrm{~mol} \mathrm{H}_{2} \mathrm{~m}^{-1} \mathrm{~s}^{-1} \mathrm{~Pa}^{-0.5}$ at $400{ }^{\circ} \mathrm{C}$, which is higher than that of pure Pd, $8.8 \times 10^{-9} \mathrm{~mol} \mathrm{H}_{2} \mathrm{~m}^{-1} \mathrm{~s}^{-1} \mathrm{~Pa}^{-0.5}$, but lower than that of pure $\mathrm{V}, 3.6 \times 10^{-7} \mathrm{~mol} \mathrm{H}_{2} \mathrm{~m}^{-1} \mathrm{~s}^{-1} \mathrm{~Pa}^{-0.5}$, by one order. Hence, the degradation of the hydrogen permeation flux of Pd-coated bcc V-based membranes in the present work either comes from the degraded catalytic efficiency of Pd layer or from the formation of the layer of deteriorated hydrogen permeability than that of V-based substrate as a result of interdiffusion [49,54].

The surface morphology of the Pd catalytic layer before and after hydrogen permeation tests is shown in Fig. 6(a)-(c). A dense and intact Pd-coating layer was confirmed before the hydrogen permeation test, as shown in Fig. 6(a). After hydrogen permeation at $623 \mathrm{~K}$ for $500 \mathrm{~h}$, a slight change in the microstructure of the surface Pd layer such as local coarsening was observed. With the hydrogen permeation test temperature increased up to $673 \mathrm{~K}$, besides the obvious Pd clusters, large Pd-V compound particles were observed locally on the surface Pdcoating layer, as illustrated by the arrows in Fig. 6(c). For characterizing the interdiffusion between the $\mathrm{Pd}$ and $\mathrm{V}_{90} \mathrm{Cr}_{5} \mathrm{Al}_{5}$ during long-term hydrogen permeation tests, the cross section of the membranes was prepared, and linear EDX analysis starting from the Pd surface (defined as position 0 ) and crossing the $\mathrm{Pd} / \mathrm{V}_{90} \mathrm{Cr}_{5} \mathrm{Al}_{5}$ interface was performed. The composition profiles are shown in Fig. 6(d)-(f), in which the microstructure of the cross section of the membranes was illustrated by inset figures. It is worth noting that falling off of the big Pd-V compound particles occurred during metallographic preparation, and that an area of less destructive Pd layer (as illustrated by the inset pictures in Fig. 6(d)-(f)) was used for EDX analysis to get more details of the composition distribution across the $\mathrm{Pd} / \mathrm{V}$ interface. Before the hydrogen permeation test, a sharp change in composition across the $\mathrm{Pd} / \mathrm{V}_{90} \mathrm{Cr}_{5} \mathrm{Al}_{5}$ interface was confirmed, as shown in Fig. 6(d). After the hydrogen permeation test at $623 \mathrm{~K}$ for $500 \mathrm{~h}$, an intermediate layer $(\sim 1 \mu \mathrm{m}$ in thickness) formed between the Pd layer and $\mathrm{V}_{90} \mathrm{Cr}_{5} \mathrm{Al}_{5}$ substrate, as shown in Fig. 6(e). The gradual variation in Pd concentration from $100 \%$ to null existed, indicating the interdiffusion between $\mathrm{Pd}$ and $\mathrm{V}_{90} \mathrm{Cr}_{5} \mathrm{Al}_{5}$. The interdiffusion between $\mathrm{Pd}$ and $\mathrm{V}_{90} \mathrm{Cr}_{5} \mathrm{Al}_{5}$ was more serious at $673 \mathrm{~K}$, and a sharp decrease of the Pd content to $\sim 65$ at $\%$ occurred at the Pd surface, as shown in Fig. 6(f). This may lead to degraded catalytic efficiency of $\mathrm{H}_{2}$ molecules at the upstream side. At the same time, the interdiffusion layer, which can be considered as V-Pd alloys of different Pd concentrations, is of lower hydrogen permeability than that of the $\mathrm{V}_{90} \mathrm{Cr}_{5} \mathrm{Al}_{5}$ base membrane $[40,58]$. The degraded surface Pd catalytic layer and the formation of interdiffusion layer are supposed to lead to hydrogen permeation flux decline during the longterm test.

XRD analysis of the $\mathrm{V}_{90} \mathrm{Cr}_{5} \mathrm{Al}_{5}$ membranes after the long-term hydrogen permeation tests was performed, as shown in Fig. 7. For the sake of comparison, the XRD pattern of the $\mathrm{V}_{90} \mathrm{Cr}_{5} \mathrm{Al}_{5}$ membrane before the test is also shown. Two phases, fcc-(Pd) and bcc-(V), were confirmed for the membrane before the test. After hydrogen permeation tests at 573 and $623 \mathrm{~K}$ for $500 \mathrm{~h}$, no new phase was detected. However, with the temperature increased up to 673 and $753 \mathrm{~K}, \mathrm{Pd}_{3} \mathrm{~V}$ and some unknown phases were detected. Moreover, a shift of the diffraction peaks of bcc-V to lower angles and Pd peaks to higher angles were observed. This clearly confirms the interdiffusion between the Pd layer and $\mathrm{V}_{90} \mathrm{Cr}_{5} \mathrm{Al}_{5}$ substrate. To maintain the integrity of the membrane after the test for further characterization, the membranes were cooled down under vacuum after the test. Hence, no hydride phase was detected in the membrane.

\subsection{Model}

To clarify the effect of the interdiffusion between $\mathrm{Pd}$ and $\mathrm{V}_{90} \mathrm{Cr}_{5} \mathrm{Al}_{5}$ on the hydrogen permeation flux, the equation taking consideration of the interdiffusion layer was used $[46,49,54]$, as follows: 


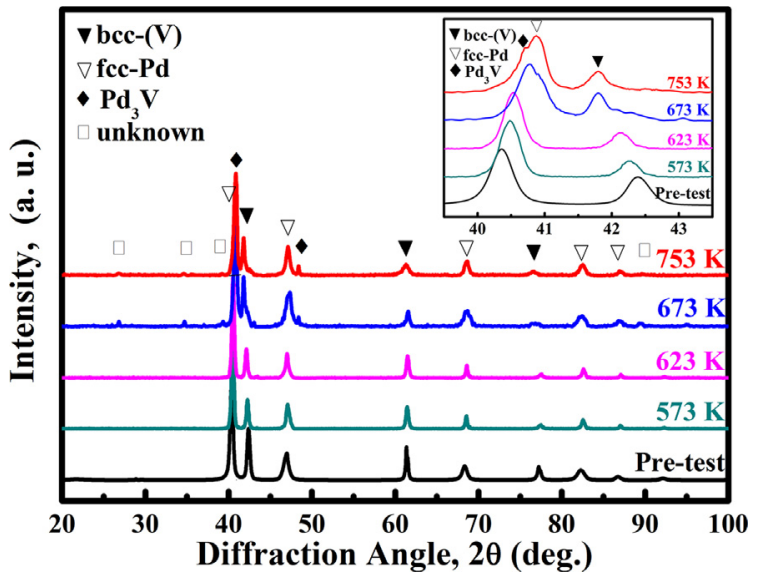

Fig. 7. XRD patterns of Pd-coated $\mathrm{V}_{90} \mathrm{Cr}_{5} \mathrm{Al}_{5}$ membranes after the hydrogen permeation tests at $573-753 \mathrm{~K}$ for $500 \mathrm{~h}$, where a shift of the diffraction peaks of bcc-(V) to lower angles and fcc-(Pd) peaks to high angles is illustrated by the inserted picture.

$P_{\mathrm{u}}=\frac{J}{Z_{H_{2}}}\left[\frac{1}{\alpha_{\mathrm{u}}}+\left(\sqrt{\frac{1}{\alpha_{d}}+\frac{Z_{H_{2}}}{J} P_{\mathrm{d}}}+\sqrt{4 Z_{H_{2}} J} \sum_{i} \frac{L_{i}}{S_{i} D_{i}}\right)^{2}\right]$

where "u" and "d" refer to the upstream and downstream side of the membrane, $P_{\mathrm{u}}$ and $P_{d}$ are the hydrogen pressure at the upstream and downstream side, $J$ is the hydrogen permeation flux through the membrane, $Z_{H_{2}}\left(=\frac{3.2}{\sqrt{T}} \mathrm{~mol} \mathrm{H}_{2} /\left(\mathrm{m}^{2} \mathrm{~s} \mathrm{~Pa}\right)\right.$ [54] is the gas kinetic theory coefficient, $\alpha_{\mathrm{u}}$ represents the probability of the dissociative sticking of $\mathrm{H}_{2}$ molecule to upstream surface followed by hydrogen solution in the metal lattice (sticking coefficient), $\alpha_{\mathrm{d}}$ is the same for the downstream side, $L_{i}$ is the thickness of each layer involved, i.e. the Pd-coating layer, substrate $\mathrm{V}_{90} \mathrm{Cr}_{5} \mathrm{Al}_{5}$ and the interdiffusion layer, $S_{i}$ and $D_{i}$ are the hydrogen solubility and diffusivity of each layer. In the present work, for the sake of simplification, $\alpha_{\mathrm{u}}$ and $\alpha_{\mathrm{d}}$ are assumed identical $\left(\alpha_{\mathrm{u}}=\alpha_{\mathrm{d}}=\alpha\right)$.

Taking the change in the structure of the $\mathrm{Pd} / \mathrm{V}_{90} \mathrm{Cr}_{5} \mathrm{Al}_{5} / \mathrm{Pd}$ membrane into consideration:

$$
\begin{aligned}
& \sum_{i} \frac{L_{i}}{S_{i} D_{i}} \\
& \quad=\left(\frac{L_{\mathrm{Pd}}}{S_{\mathrm{Pd}} D_{\mathrm{Pd}}}\right)_{\mathrm{u}}+\left(\frac{L_{\text {int }}}{S_{\mathrm{int}} D_{\text {int }}}\right)_{\mathrm{u}}+\left(\frac{L_{\mathrm{V}}}{S_{\mathrm{V}} D_{\mathrm{V}}}\right)+\left(\frac{L_{\text {int }}}{S_{\text {int }} D_{\text {int }}}\right)_{\mathrm{d}}+\left(\frac{L_{\mathrm{Pd}}}{S_{\mathrm{Pd}} D_{\mathrm{Pd}}}\right)_{\mathrm{d}}
\end{aligned}
$$

where $L_{\mathrm{Pd}}, L_{\mathrm{V}}, L_{\text {int }}, S_{\text {Pd }}, S_{\mathrm{V}}, S_{\text {int }}, D_{\text {Pd }}, D_{\mathrm{V}}$, and $D_{\text {int }}$ are the thickness, solubility and diffusivity of the Pd layer, V-based alloy and the interdiffusion layer respectively. In the present work, the thickness of the Pd coating layer, $L_{\mathrm{Pd}}$, is $900 \mathrm{~nm}$, and the thickness of the $\mathrm{V}_{90} \mathrm{Cr}_{5} \mathrm{Al}_{5}$ substrate, $L_{\mathrm{V}}$, is $0.6 \mathrm{~mm}$. The hydrogen solubility and hydrogen diffusivity are based on the experimental results, as e.g. from Figs. 2-4. For the calculation at $673 \mathrm{~K}$ in the present work, $S_{\mathrm{Pd}} \times D_{\mathrm{Pd}}=3.13 \times 10^{-8} \mathrm{~mol}$ $\mathrm{H} \mathrm{m}^{-1} \mathrm{~s}^{-1} \mathrm{~Pa}^{-0.5}$ from Ref. [54] is used. At $673 \mathrm{~K}$, the hydrogen permeability in V-Pd compounds is $\sim 10$ times lower than that in pure V [40]. Hence, the layers formed due to the interdiffusion are expected to exhibit much lower hydrogen permeability than the original Pd coating layer, which plays a critical role in the degradation of hydrogen permeation flux shown in Fig. 5. However, the hydrogen solubility and diffusivity of the interdiffusion layer are not known, which makes it hard to do the calculation based on Eqs. (4) and (5).

For analyzing the influence of the interdiffusion on the hydrogen permeation behavior, experimentally, three different types of $\mathrm{Pd} /$ $\mathrm{V}_{90} \mathrm{Cr}_{5} \mathrm{Al}_{5} / \mathrm{Pd}$ membranes were made and then submitted to hydrogen permeation tests at $673 \mathrm{~K}$, as shown in Fig. 8. The membrane consisting of Pd layers on both sides of the $\mathrm{V}_{90} \mathrm{Cr}_{5} \mathrm{Al}_{5}$ alloy, defined as pre-test membrane, is defined as \#1. Considering the formation of the

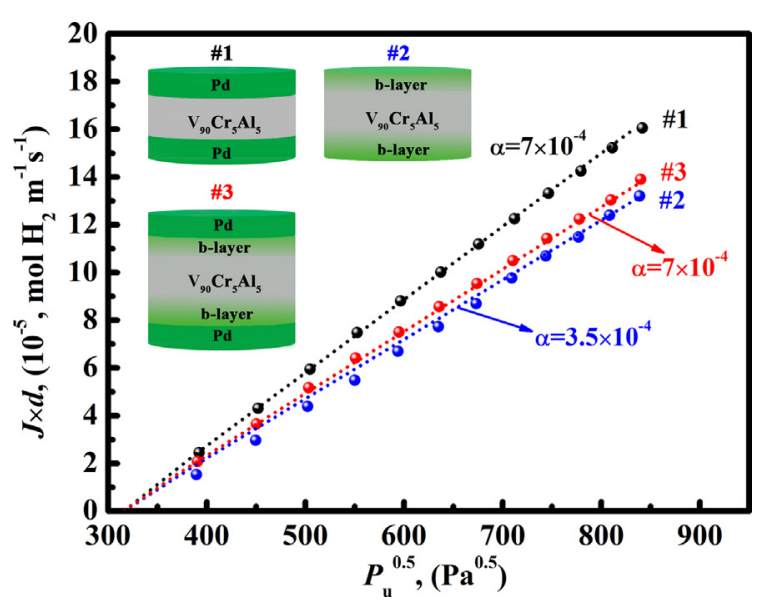

Fig. 8. Dependence of the normalized hydrogen permeation flux $\left(\begin{array}{l}J \times d \\ \text { ( }\end{array}\right)$ through the membranes on the $\mathrm{H}_{2}$ pressure, $P_{\mathrm{u}}^{0.5}$ at $673 \mathrm{~K}$. Solid dots - experimental datum, dotted line - the calculation with Eqs. (4)-(6) with different sticking coefficients.

interdiffusion layer of $\mathrm{Pd} / \mathrm{V}_{90} \mathrm{Cr}_{5} \mathrm{Al}_{5} / \mathrm{Pd}$ membranes during the hydrogen permeation test, membrane $\# 2$, which presents the state of membrane \#1 but after annealing in the $\mathrm{H}_{2}$ atmosphere with a $\mathrm{H}_{2}$ partial pressure of $0.7 \mathrm{MPa}$ at $673 \mathrm{~K}$ for 4 days, was prepared. The membrane \#2 consists of surface Pd catalytic layer, the interdiffusion layer and the $\mathrm{V}_{90} \mathrm{Cr}_{5} \mathrm{Al}_{5}$ layer, as shown by the inset illustration in Fig. 8. For recovering the catalytic effect of Pd layer, electroless plating of membrane \#2 was performed to produce dense Pd-coating layers at both sides, and this membrane with new Pd catalytic layers was termed as \#3, as shown in Fig. 8. The hydrogen permeation tests of the same procedure were carried out on the three membranes at $673 \mathrm{~K}$. The duration of each test was $3 \mathrm{~h}$. As shown in Fig. 8, membrane \#1 exhibits the highest hydrogen permeation. The reduction of the hydrogen permeation flux between membrane \#1 and \#2 demonstrates the degradation induced by the formation of the interdiffusion layer and change in the surface Pd-coating layer. Membrane \#3 exhibits a slightly improved hydrogen flux in comparison with membrane \#2, but still lower than that of membrane \#1. The slightly improvement in comparison with membrane $\# 2$, on one hand, indicates the recovery of the hydrogen dissociation/association due to the new dense Pd layer, and on the other hand, means that the hydrogen flux degradation of membrane 2 mainly comes from the formation of interdiffusion layer. The lower hydrogen flux of membrane \#3 in comparison with membrane \#1 suggests the degradation induced by the interdiffusion layer.

Considering that the duration of the test for membrane $\# 1$ is $3 \mathrm{~h}$, and a linear relationship between $J \times d$ and $P_{\mathrm{u}}{ }^{0.5}$ maintained until the end of the test, i.e. not obvious degradation of hydrogen flux, the formation of the interdiffusion layers and their influence were neglected. Eq. (5) was simplified as follows:

$\sum_{i} \frac{L_{i}}{S_{i} D_{i}}=\left(\frac{L_{\mathrm{Pd}}}{S_{\mathrm{Pd}} D_{\mathrm{Pd}}}\right)_{\mathrm{u}}+\left(\frac{L_{\mathrm{V}}}{S_{\mathrm{V}} D_{\mathrm{V}}}\right)+\left(\frac{L_{\mathrm{Pd}}}{S_{\mathrm{Pd}} D_{\mathrm{Pd}}}\right)_{\mathrm{d}}$

Combining Eqs. (4) and (6), the hydrogen permeation flux through membrane \#1 can be calculated based on the experimental results (Figs. 2-4). For membrane \#1, a sticking coefficient $\alpha=7 \times 10^{-4}$ was derived based on the experimental measurements, which is consistent with the work of Alimove et al. $[46,49]$. In the present work, the sticking coefficient $\alpha$ of membrane \#3 is expected to the same as that of membrane \#1 due to the recoated Pd layer. Based on this assumption, the experimentally measured hydrogen flux of membrane \#3, the value of $\left(\frac{S_{\text {int }} D_{\text {int }}}{L_{\text {int }}}\right)$, i.e. the influence of the interdiffusion layer, can be obtained. The inhibition of interdiffusion layers which causes the inevitable increase of the sum in Eq. (5) leads to 1.4 times (which is acquired from the fitting of the experimental results) of the sum of Eq. (6). 
Due to the pronounced roughness of the Pd layer after electroless plating, similar as in the previous work [49], it is not straightforward to measure the thickness of the interdiffusion layer of the degraded membranes $\mathrm{Pd}(0.9 \mu \mathrm{m}) / \mathrm{V}_{90} \mathrm{Cr}_{5} \mathrm{Al}_{5}(0.6 \mathrm{~mm}) / \mathrm{Pd}(0.9 \mu \mathrm{m})$ after 4 days of heat treatment. This makes it difficult to characterize the hydrogen solubility and diffusivity of the interdiffusion layer. A sticking coefficient for membrane $\# 2, \alpha=3.5 \times 10^{-4}$, was derived through Eqs. (4) and (5) based on the experimental results of membrane \#2 and the value of $\left(\frac{S_{\text {int }} D_{\text {int }}}{L_{\text {int }}}\right)$ discussed above, as shown in Fig. 8, which follows the variation tendency of the sticking coefficient in Ref. [37,38]. It is worth noting that a deviation of the dependency between $J \times d$ and $P_{\mathrm{u}}^{0.5}$ from the linear relationship was observed for membrane \#2 and \#3. With increasing upstream hydrogen pressure, the difference in hydrogen flux between membrane \#2 and \#3 becomes smaller, indicating a weak influence of Pd agglomeration or surface saturation on the hydrogen permeation flux under high hydrogen pressure. This is consistent with Refs. $[46,49,66]$ that hydrogen prefers to chemisorb on the defects on the metal surface than on the clean metal surface. The barrier layer formed due to the interdiffusion between $\mathrm{Pd}$ and $\mathrm{V}-\mathrm{Cr}$-Al is the main reason for the decay in the hydrogen permeation flux at $673 \mathrm{~K}$.

\section{Conclusions}

Alloying of $\mathrm{V}$ using $\mathrm{Cr}$ and $\mathrm{Al}$ based on the principle of lattice matching has been carried out, which has been demonstrated to reduce the hydrogen absorption while maintaining the high hydrogen permeability similar to pure vanadium. The $\mathrm{V}_{90} \mathrm{Cr}_{5} \mathrm{Al}_{5}$ alloy exhibits a significantly reduced hydrogen solubility, but a slightly reduced hydrogen diffusivity in comparison with pure $\mathrm{V}$, resulting from a similar lattice parameter as that of pure $\mathrm{V}$. The long-term stability of the $\mathrm{V}_{90} \mathrm{Cr}_{5} \mathrm{Al}_{5}$ membrane at temperatures of 623 and $673 \mathrm{~K}$ was investigated. Excellent stability at $623 \mathrm{~K}$ with a hydrogen permeation flux of $1.3 \times 10^{-4} \mathrm{~mol} \mathrm{H}_{2} \mathrm{~m}^{-1} \mathrm{~s}^{-1}$ after $500 \mathrm{~h}$ was confirmed. With increasing operating temperature up to $673 \mathrm{~K}$, a degradation of the hydrogen permeation flux was experimentally observed during long-term permeation tests. By analyzing the obtained experimental results, it is found that the formation of barrier layers at the $\mathrm{Pd} / \mathrm{V}_{90} \mathrm{Cr}_{5} \mathrm{Al}_{5}$ interfaces induced by interdiffusion between $\mathrm{Pd}$ and $\mathrm{V}_{90} \mathrm{Cr}_{5} \mathrm{Al}_{5}$ is the main reason of the degradation in the hydrogen permeation flux.

\section{CRediT authorship contribution statement}

Feifei Huang: Investigation, Data curation, Writing - original draft. Xinzhong Li: Conceptualization, Funding acquisition, Methodology, Resources, Supervision, Writing - review \& editing, Project administration. Xingrun Shan: Investigation. Jingjie Guo: Resources. Fausto Gallucci: Resources, Writing - review \& editing. Martin van Sint Annaland: Resources, Writing - review \& editing. Dongmei Liu: Conceptualization, Supervision, Writing - review \& editing.

\section{Acknowledgments}

This project was supported by the National Natural Science Foundation of China (Grants Nos. 51771066, 51571075 and 51274077) and the China Scholarship Council (CSC).

\section{Declaration of Competing Interest}

Authors declare that there is no potential conflict of interests.

\section{References:}

[1] J.W. Phair, S.P.S. Badwal, Review of proton conductors for hydrogen separation, Ionics 12 (2006) 103-115.

[2] L. Chen, L. Zhuang, J. Xue, Y. Wei, H. Wang, Tuning the separation performance of hydrogen permeable membranes using an anion doping strategy, J, Mater, Chem, A
5 (2017) 20482-20490.

[3] J. Xue, Y. Chen, Y. Wei, A. Feldhoff, H. Wang, J. Caro, Gas to liquids: natural gas conversion to aromatic fuels and chemicals in a hydrogen-permeable ceramic hollow fiber membrane reactor, ACS Catal. 6 (2016) 2448-2451.

[4] S. Tosti, Supported and laminated Pd-based metallic membranes, Int. J. Hydrogen Energy 28 (2003) 1445-1454.

[5] E. Fernandez, K. Coenen, A. Helmi, J. Melendez, J. Zuñiga, D.A.P. Tanaka, M. van Sint Annaland, F. Gallucci, Preparation and characterization of thin-film Pd-Ag supported membranes for high-temperature applications, Int. J. Hydrogen Energy 40 (2015) 13463-13478.

[6] Ø. Hatlevik, S.K. Gade, M.K. Keeling, P.M. Thoen, A.P. Davidson, J.D. Way, Palladium and palladium alloy membranes for hydrogen separation and production: history, fabrication strategies, and current performance, Sep. Purif. Technol. 73 (2010) 59-64.

[7] F. Gallucci, M. van Sint Annaland, J.A.M. Kuipers, Theoretical comparison of packed bed and fluidized bed membrane reactors for methane reforming, Int. J. Hydrogen Energy 35 (2010) 7142-7150.

[8] A. Arratibel, D.A. Pacheco Tanaka, T. Slater, T.L. Burnett, M. van Sint Annaland, F. Gallucci, Unravelling the transport mechanism of pore-filled membranes for hydrogen separation, Sep. Purif. Technol. 203 (2018) 41-47.

[9] M.D. Dolan, Non-Pd BCC alloy membranes for industrial hydrogen separation, J. Membr. Sci. 362 (2010) 12-28.

[10] A. Santucci, S. Tosti, A. Basile, 4 - Alternatives to palladium in membranes for hydrogen separation: nickel, niobium and vanadium alloys, ceramic supports for metal alloys and porous glass membranes, Handbook Membrane Reactors 1 (2013) 183-217.

[11] J.Y. Yang, M. Komaki, C. Nishimura, Effect of overlayer thickness on hydrogen permeation of $\mathrm{Pd}_{60} \mathrm{Cu}_{40} / \mathrm{V}$-15Ni composite membranes, Int. J. Hydrogen Energy 32 (2007) 1820-1824.

[12] M.D. Dolan, M.E. Kellam, K.G. McLennan, D. Liang, G. Song, Hydrogen transport properties of several vanadium-based binary alloys, Int. J. Hydrogen Energy 38 (2013) 9794-9799.

[13] T.M. Adams, J. Mickalonis, Hydrogen permeability of multiphase V-Ti-Ni metallic membranes, Mater. Lett. 61 (2007) 817-820.

[14] G. Song, M.D. Dolan, M.E. Kellam, D. Liang, S. Zambelli, V-Ni-Ti multi-phase alloy membranes for hydrogen purification, J. Alloys Compd. 509 (2011) 9322-9328.

[15] M.D. Dolan, G. Song, K.G. McLennan, M.E. Kellam, D. Liang, The effect of Ti on the microstructure, hydrogen absorption and diffusivity of V-Ni alloy membranes, J. Membr. Sci. 415-416 (2012) 320-327.

[16] E. Fleury, J. Suh, D. Kim, C.H. Jeong, J.H. Park, Hydrogen permeation characteristics of rolled $\mathrm{V}_{85} \mathrm{Al}_{10} \mathrm{Co}_{5}$ alloys, Curr. Appl. Phys. 12 (2012) 1131-1138.

[17] Y. Lee, C. Ouyang, J. Suh, E. Fleury, Y.W. Cho, J. Shim, Role of alloying elements in vanadium-based binary alloy membranes for hydrogen separation, J. Membr. Sci. 423-424 (2012) 332-341.

[18] M.D. Dolan, S.S. Hia, L.D. Morpeth, Design and operational considerations for a catalytic membrane reactor incorporating a vanadium-based membrane, Sep. Purif. Technol. 147 (2015) 398-405.

[19] M.D. Dolan, M.A. Kochanek, C.N. Munnings, K.G. McLennan, D.M. Viano, Hydride phase equilibria in V-Ti-Ni alloy membranes, J. Alloys Compd. 622 (2015) 276-281.

[20] J. Oh, W. Ko, J. Suh, Y. Lee, B. Lee, W.Y. Yoon, J. Shim, Enhanced high temperature hydrogen permeation characteristics of V-Ni alloy membranes containing a trace amount of yttrium, Scripta Mater. 116 (2016) 122-126.

[21] A. Voyt, N. Sidorov, I. Sipatov, M. Dobrotvorskii, V. Piven, I. Gabis, Hydrogen solubility in $\mathrm{V}_{85} \mathrm{Ni}_{15}$ alloy, Int. J. Hydrogen Energy 42 (2017) 3058-3063.

[22] A. Suzuki, H. Yukawa, T. Nambu, Y. Matsumoto, Y. Murata, Alloy design of V-based hydrogen permeable membrane under given temperature and pressure condition, Int. J. Hydrogen Energy 42 (2017) 22325-22329.

[23] R. Kawai, H. Yukawa, A. Suzuki, T. Nambu, Y. Murata, Alloying effects of Fe and A] on formation and decomposition temperatures of vanadium hydride, $\mathrm{V}_{2} \mathrm{H}$, Int. J. Hydrogen Energy 42 (2017) 22564-22574.

[24] X. Li, F. Huang, D. Liu, X. Liang, R. Chen, M. Rettenmayr, Y. Su, J. Guo, H. Fu, V-Cr$\mathrm{Cu}$ dual-phase alloy membranes for hydrogen separation: An excellent combination of ductility, hydrogen permeability and embrittlement resistance, J. Membr. Sci. 524 (2017) 354-361.

[25] S. Tosti, A. Santucci, A. Pietropaolo, S. Brutti, O. Palumbo, F. Trequattrini, A. Paolone, Hydrogen sorption properties of $\mathrm{V}_{85} \mathrm{Ni}_{15}$, Int. J. Hydrogen Energy 43 (2018) 2817-2822.

[26] K.H. Kim, H.C. Park, J. Lee, E. Cho, S.M. Lee, Vanadium alloy membranes for high hydrogen permeability and suppressed hydrogen embrittlement, Scripta Mater. 68 (2013) 905-908.

[27] J. Shim, W. Ko, K. Kim, H. Lee, Y. Lee, J. Suh, Y.W. Cho, B. Lee, Prediction of hydrogen permeability in V-Al and V-Ni alloys, J. Membr. Sci. 430 (2013) 234-241.

[28] S.I. Jeon, E. Magnone, J.H. Park, Y. Lee, The effect of temperature and pressure on the hydrogen permeation through Pd-coated $\mathrm{Ti}_{26} \mathrm{Ni}_{21} \mathrm{~V}_{53}$ alloy membrane under different atmospheres, Mater. Lett. 65 (2011) 2495-2497.

[29] E. Magnone, S.I. Jeon, J.H. Park, E. Fleury, Relationship between microstructure and hydrogen permeation properties in the multiphase $\mathrm{Ni}_{21} \mathrm{Ti}_{23} \mathrm{Nb}_{56}$ alloy membranes, J. Membr. Sci. 384 (2011) 136-141.

[30] X. Li, E. Yan, M. Rettenmayr, D. Liu, Y. Su, J. Guo, Hydrogen permeation behavior of $\mathrm{Nb}_{30} \mathrm{Ti}_{35} \mathrm{Ni}_{35-\mathrm{x}} \mathrm{Co}_{\mathrm{x}}(\mathrm{x}=0 \ldots 35)$ alloys containing high fractions of eutectic, Int. J. Hydrogen Energy 39 (2014) 9366-9374.

[31] D. Liu, X. Li, H. Geng, R. Chen, M. Rettenmayr, Y. Su, H. Li, J. Guo, H. Fu, Development of $\mathrm{Nb}_{35} \mathrm{Mo}_{5} \mathrm{Ti}_{30} \mathrm{Ni}_{30}$ alloy membrane for hydrogen separation applications, J. Membr. Sci. 553 (2018) 171-179.

[32] A.M. Patselov, V.V. Rybin, B.A. Greenberg, N.V. Mushnikov, Hydrogen absorption 
in as-cast bcc single-phase Ti-Al-Nb alloys, J. Alloys Compd. 505 (2010) 183-187.

[33] Y. Liu, L. Zhang, Y. Du, J. Wang, D. Liang, Study of atomic mobilities and diffusion characteristics in bcc Ti-Ta and Ta-W alloys, Calphad 34 (2010) 310-316.

[34] S. Gahr, H.K. Birnbaum, Hydrogen embrittlement of niobium-III. High temperature behavior, 1978

[35] Y. Matsumoto, H. Yukawa, T. Nambu, 12 - In situ quantitative evaluation of hydrogen embrittlement in group 5 metals used for hydrogen separation and purification, Adv. Hydrogen Prod., Storage Distrib. (2014) 317-340.

[36] S.K. Dwivedi, M. Vishwakarma, Hydrogen embrittlement in different materials: a review, Int. J. Hydrogen Energy 43 (2018) 21603-21616.

[37] S.B. Lundin, N.S. Patki, T.F. Fuerst, C.A. Wolden, J.D. Way, Inhibition of hydrogen flux in palladium membranes by pressure-induced restructuring of the membrane surface, J. Membr. Sci. 535 (2017) 70-78.

[38] B.H. Howard, R.P. Killmeyer, K.S. Rothenberger, A.V. Cugini, B.D. Morreale, R.M. Enick, F. Bustamante, Hydrogen permeance of palladium-copper alloy membranes over a wide range of temperatures and pressures, J. Membr. Sci. 241 (2004) 207-218.

[39] M.D. Dolan, D.M. Viano, M.J. Langley, K.E. Lamb, Tubular vanadium membranes for hydrogen purification, J. Membr. Sci. 549 (2018) 306-311.

[40] S.N. Paglieri, J.R. Wermer, R.E. Buxbaum, M.V. Ciocco, B.H. Howard, B.D. Morreale, Development of membranes for hydrogen separation: Pd coated V-10Pd, Energy Mater. 3 (2008) 169-176.

[41] T. Ozaki, Y. Zhang, M. Komaki, C. Nishimura, Hydrogen permeation characteristics of V-Ni-Al alloys, Int. J. Hydrogen Energy 28 (2003) 1229-1235.

[42] D.A. Cooney, J.D. Way, C.A. Wolden, A comparison of the performance and stability of Pd/BCC metal composite membranes for hydrogen purification, Int. J. Hydrogen Energy 39 (2014) 19009-19017.

[43] Y. Zhang, M. Komaki, C. Nishimura, Morphological study of supported thin Pd and Pd-25Ag membranes upon hydrogen permeation, J. Membr. Sci. 246 (2005) $173-180$.

[44] N. Ohtsu, K. Ishikawa, Y. Kobori, Hydrogen permeability degradation of Pd-coated Nb-TiNi alloy caused by its interfacial diffusion, Appl. Surf. Sci. 360 (2016) 566-571.

[45] M.V. Mundschau, X. Xie, C.R. Evenson, A.F. Sammells, Dense inorganic membranes for production of hydrogen from methane and coal with carbon dioxide sequestration, Catal. Today 118 (2006) 12-23.

[46] V.N. Alimov, Y. Hatano, A.O. Busnyuk, D.A. Livshits, M.E. Notkin, A.I. Livshits, Hydrogen permeation through the Pd-Nb-Pd composite membrane: Surface effects and thermal degradation, Int. J. Hydrogen Energy 36 (2011) 7737-7746.

[47] K. Sasaki, M. Hattori, K. Tsuchimoto, H. Yukawa, S. Arai, T. Tokunaga, Y. Murata, T. Yamamoto, Microstructural analysis of thermal degradation of palladium-coated niobium membrane, J. Alloys Compd. 573 (2013) 192-197.

[48] F. Li, B. Zhong, H. Xiao, X. Ye, L. Lu, W. Guan, Y. Zhang, X. Wang, C. Chen, Effect of degassing treatment on the deuterium permeability of Pd-Nb-Pd composite membranes during deuterium permeation, Sep. Purif. Technol. 190 (2018) 136-142.

[49] V.N. Alimov, A.O. Busnyuk, M.E. Notkin, A.I. Livshits, Pd-V-Pd composite membranes: Hydrogen transport in a wide pressure range and mechanical stability, J. Membr. Sci. 457 (2014) 103-112.

[50] S. Uemiya, Brief review of steam reforming using a metal membrane reactor, Top. Catal. 29 (2004) 79-84.

[51] S. Bellini, X. Liang, X. Li, F. Gallucci, A. Caravella, Non-ideal hydrogen permeation through V-alloy membranes, J. Membr. Sci. 564 (2018) 456-464.

[52] V.N. Alimov, I.V. Bobylev, A.O. Busnyuk, M.E. Notkin, E.Yu. Peredistov, A.I. Livshits, Hydrogen transport through the tubular membranes of V-Pd alloys: Permeation, diffusion, surface processes and WGS mixture test of membrane assembly, J. Membr. Sci. 549 (2018) 428-437.

[53] J. Smith, D. Bailey, O. Carlson, The Cr-V (Chromium-Vanadium) system, J. Phase Equilib. 2 (1982) 469-473.

[54] H. Okamoto, Al-V (Aluminum-Vanadium), J. Phase Equilibria Diffus. 33 (2012) 491.

[55] X. Li, F. Huang, Y. Su, J. Guo, M. Rettenmayr, D. Liu, Development of dual-phase $\mathrm{V}_{90} \mathrm{Fe}_{5} \mathrm{Al}_{5} / \mathrm{Cu}$ alloys for enhanced malleability and sustainable hydrogen permeability, J. Membr. Sci. 591 (2019) in press.

[56] J.F. Lynch, J.J. Reilly, F. Millot, The absorption of hydrogen by binary vanadiumchromium alloys, J. Phys. Chem. Solids 39 (1978) 883-890.

[57] K. Kim, J. Shim, B. Lee, Effect of alloying elements (Al Co, Fe, Ni) on the solubility of hydrogen in vanadium: A thermodynamic calculation, Int. J. Hydrogen Energy 37 (2012) 7836-7847.

[58] V.N. Alimov, A.O. Busnyuk, M.E. Notkin, E.Y. Peredistov, A.I. Livshits, Hydrogen transport through V-Pd alloy membranes: Hydrogen solution, permeation and diffusion, J. Membr. Sci. 481 (2015) 54-62.

[59] D.T. Peterson, S.O. Nelson, Isopiestic solubility of hydrogen in vanadium alloys at low temperatures, Metall. Trans. A 16 (1985) 367-374.

[60] S.I. Jeon, J.H. Park, E. Magnone, Y.T. Lee, E. Fleury, Hydrogen permeation of Pdcoated $\mathrm{V}_{90} \mathrm{Al}_{10}$ alloy membranes at different pressures in the presence and absence of carbon dioxide, Curr. Appl. Phys. 12 (2012) 394-400.

[61] W. Ko, J. Oh, J. Shim, J. Suh, W.Y. Yoon, B. Lee, Design of sustainable V-based hydrogen separation membranes based on grain boundary segregation, Int. J. Hydrogen Energy 39 (2014) 12031-12044.

[62] Y. Nakamura, H. Yukawa, A. Suzuki, T. Nambu, Y. Matsumoto, Y. Murata, Alloying effects on hydrogen permeability of V without catalytic Pd overlayer, J. Alloys Compd. 645 (2015) S275-S279.

[63] T.B. Flanagan, D. Wang, Hydrogen solubilities and permeabilities in fcc Pd-Al and $\left(\mathrm{Pd}_{0.77} \mathrm{Ag}_{0.23}\right)_{1-\mathrm{x}} \mathrm{Al}_{\mathrm{x}}$ alloys (393-523 K), J. Alloys Compd. 767 (2018) 1264-1270.

[64] R. Kirchheim, Hydrogen solubility and diffusivity in defective and amorphous metals, Prog Mater Sci. 32 (1988) 261-325.

[65] Y. Fukai, H. Sukimoto, Diffusion of hydrogen in metals, Adv. Phys. 34 (1985) 263-326.

[66] R. Van Lent, S.V. Auras, K. Cao, A.J. Walsh, M.A. Gleeson, L.B.F. Juurlink, Sitespecific reactivity of molecules with surface defects-the case of $\mathrm{H}_{2}$ dissociation on Pt, Science 363 (2019) 155-157. 